\title{
DEVELOPMENT OF WEB APPLICATION FOR PACKAgINg Design
}

\author{
Rawiphon Charunphankasem \\ Multimedia Technology, Department of Mass Communication Technology, \\ Rajamangala University of Technology Phra Nakhon, Bangkok, Thailand
}

\begin{abstract}
The majority of One Tambon One Product (OTOP) entrepreneurs desired a new packaging design that attracts the attention of consumers. The aims of this research were to 1) determine the packaging demands of entrepreneurs, 2) develop a conceptual framework for web applications, and 3) create web applications. Finally, 4) to ascertain entrepreneurs' satisfaction with the use of web applications in packaging design. The demographic and sample were recruited from the central region's population, entrepreneurs, and customers. Purposive sampling was used to choose 400 entrepreneurs and customers in Saraburi province. The main result was that requirement of entrepreneursabout package must be easy to portable. And Web Application must be also easy to use. By opinion of experts the result of web application development was overall high level and satisfaction of web application that help entrepreneurs to design package was high level. So the benefit of research is that entrepreneurs had web application to design the package and lower cost.
\end{abstract}

\section{KEYWORDS}

Web Application, Packaging Design

\section{INTRODUCTION}

Nowadays, technology has become an integral part of our lives. The advancement of technology has altered the landscape of the world. Today, we enter the information technology era, which will impact science advancement in every industry, including work, medicine, commerce, business, entertainment, education, and communication. The global community places a premium on investment in information and communication technology: ICT [1]

As much as companies are concerned, the web application is akin to a key to every brand. That is why the web application should also be professional in appearance and serve as a reflection of the customer's business. Prior to developing any web application, we need to gather all relevant information about the web application that will be developed, as well as the customer's requirements. Depending on the website, a suitable model for developing the web application should be chosen. After discussing the process, we will adhere to a specific software development architectural pattern based on the requirements gathered from the customer. The most critical aspect of designing a web application is selecting the suitable programming language for development and the framework for making the website more secure and userfriendly. [2]. A comprehensive approach is required for the web application, which encompasses numerous facets, including technical, organizational, and legal/philosophical dimensions. As a result, information processing methodologies, techniques, and tools have been extended to facilitate the development of these types of applications, for example, Object-Oriented Web Solutions. Abstract modeling techniques have been used to define needs for web-based software development processes abstractly; for example, use cases and scenarios have been applied to 
The International Journal of Multimedia \& Its Applications (IJMA) Vol.13, No. 5, October 2021

functional model requirements. [3] According to the study, 400 OTOPentrepreneurs in Thailand expressed frustration with the inability to create their own product packaging. As a result, the manufacturing cost is relatively high. Additionally, they were questioned about their use of mobile phones. We discovered that the majority of entrepreneurs now use cell phones. From the aforementioned issues, the researcher came up with the idea of developing a web application to assist entrepreneurs in designing OTOP packaging for internationalization, which is expected to contribute to community economic growth by upgrading community products to larger markets at the Association of South East Asian Nations ( ASEAN) and international levels, thereby increasing the opportunity for OTOPproduct. This is a cultural product that will add to the country's strength.

\section{Population and Sample}

\subsection{Sample selection procedure and method}

The population for this study was composed of individuals with at least five years of relevant experience, which included six OTOP product specialists, six packaging design specialists, and five web application design specialists, for a total of seventeen individuals. The specialists used in the process of media synthesis and quality determination are those with a doctoral degree or an academic position equivalent to an assistant professor in computer science or a related field, or those with at least ten years of teaching experience, for a total of five people. Purposive sampling in Saraburi Province was used to select 400 consumers and entrepreneurs for this study. Interview guides and questionnaires were used as research instruments.

\subsection{Measuring characteristics of variables}

The measurement of variable characteristics consisted of entrepreneurs' satisfaction, consumers' satisfaction, the efficiency of web applications for designing OTOP product packaging to promote marketing, and entrepreneurs' satisfaction towards the use of web applications for OTOP product packaging design to promote marketing.

\subsection{Reliability and Accuracy}

2.3.1. A questionnaire on the packaging needs of consumers and entrepreneurs was developed from the collection of Define questions in accordance with the research objectives. Then a questionnaire was created and pre-tested with 40 samples to test their reliability. Additionally, determine the reliability coefficient for Cronbach's Alpha Coefficient, which must be greater than 0.7 . The reliability of the questionnaire used in the trial is 0.85 .

2.3.2. An in-depth interview with packaging design specialists and web application specialists on OTOP product packaging design issues and determine the tool's quality by checking the content validity by having experts review content, consistency, content coverage, and the correctness and appropriateness of the questions.

2.3.3. A Form for Evaluating the Performance of a Web Application. The researcher developed a Web Application Effectiveness Assessment Scale as a five-level Rating Scale encompassing the following: 1) web applications that are simple to use; 2) web applications that are stable in use; and 3) web applications that can be used on a variety of platforms. 4) Web applications use the appropriate color scheme for their intended audience 5) Web-based applications utilize the proper screen size 6) This web application 
The International Journal of Multimedia \& Its Applications (IJMA) Vol.13, No. 5, October 2021

is beneficial to users. 7) Overall satisfaction. The researcher presented the web application performance evaluation form to five experts to verify the content validity, determine the IOC (Index of Item-Objective Congruence), and discovered that each item has a value between $0.67-1.00$, which is greater than 0.50 , indicating that the web application is usable.

2.3.4. A survey of entrepreneurs' satisfaction with web applications for packaging design. The researcher developed a Web Application Effectiveness Assessment Scale as a five-level rating scale covering the use of web applications in packaging design. The scale was developed by collecting and defining questions according to the research objectives and pre-testing with a group of twenty samples to determine the scale's reliability and confidence coefficient of Cronbach's Alpha Coefficient, which has acceptance criteria of 0.7 or more. The questionnaire used in the pre-test had reliability equal to 0.73 .

\subsection{Statistics used in research}

1. Qualitative data analysis is a form of content analysis in which the researcher extracts information from an in-depth interview by paraphrasing it, then compiles and synthesizes it to facilitate interpretation. Summarize and present the findings in accordance with the issues.

2. Quantitative data analysis: after the researcher collected field data via questionnaire, all data were selected, organized, grouped, and analyzed by computer using a statistical program and descriptive statistics, including frequency and percentage.

\section{DEVELOP WEB APPLICATION}

The development of Web Application adhered to the ADDIE model's design principles [4], and the draft Web Application design was sent to experts with doctorate degrees or academic positions equivalent to Assistant Professor in computer science or related fields, or who have at least ten years of teaching experience. Five individuals evaluated the media's efficiency [5] and noted that the background color style, font, screen size, usage menu, image recording format, photo printing pattern, interactive buttons within web applications, and content within web applications all contributed to the efficiency of the media. It should be incorporated into the development of web applications and can be used to benefit consumers and entrepreneurs. Regarding packaging and labels designed with color patterns, patterns, and characters, they can be used in real life, and it was suggested that we add a print and save format that allows for saving as.png and.pdf files.

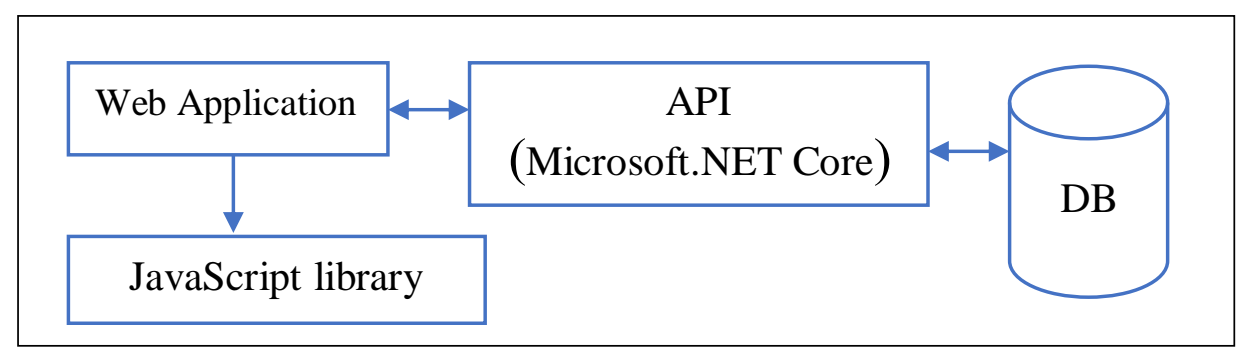

Figure 1. System structure of the De-otop Web application

Web applications are developed in two primary languages: JavaScript library [6], which is used to create applications, and Microsoft.NET Core [7], which is used to create servers that communicate with databases and other applications. Apps, also known as Used to write APIs (APIs) for the PostgreSQL database. 
The International Journal of Multimedia \& Its Applications (IJMA) Vol.13, No. 5, October 2021

API design with Visual Studio 2019 is a tool for developing APIs in the.NET Core programming language. It consists of establishing a database connection, managing data, and transmitting data to the database via an API. .NET Core will use an intermediary called Entity Framework to communicate with the database. Any Entity Framework method that saves or retrieves data will be invoked via Entity Framework.

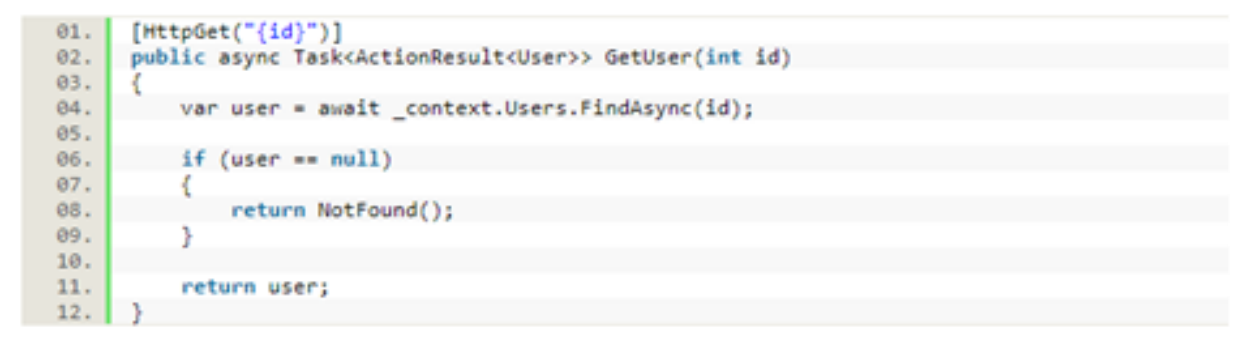

Figure 2. An illustration of how to retrieve user data from the User API.

Figure 2 illustrates how the Entity Framework's "_context.User.FindAsync" method is used to retrieve user information by ID.

The information that requires saving or editing the database is managed via the Entity Framework. However, if the data is of a media type such as images or files, it is saved to the server, partitioning it according to the recorder's ID.

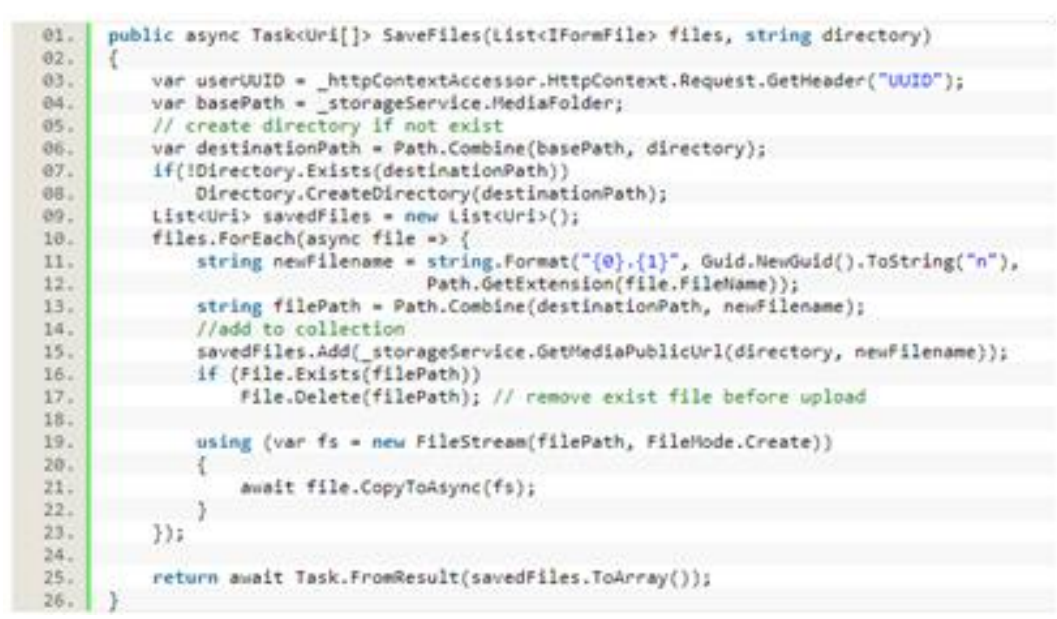

Figure 3. File Management Functionality

API traffic, which will be received as JSON via HTTP from the application, will consist of nine endpoints with the following HTTP traffic types: POST, GET, PUT, and DELETE.

Because the database is managed by the Entity Framework, a Code-First approach is used to design it, which is a method for designing a database without having to know the language used to write the database, which is the Code-First principle used to write a model first, which is also used as a database structure.

After running the commands dotnet migration dt-user and update-database at the Terminal, the User database will be automatically created in the PostgreSQL database. This step will define the program's appearance. The program page will be designed by a designer using the principles of Google Material Design, resulting in a simple and easy-to-use program page. The language used 
The International Journal of Multimedia \& Its Applications (IJMA) Vol.13, No. 5, October 2021

to develop applications is ReactJS, which is extremely powerful in terms of user interaction and data access and runs on all platforms. The program is divided into two sections: the front-end and the administrative back end (Dashboard).

Three structures comprise the front-end systems: A Header zone, a Content zone, and a Footer zone, which is also a Header zone. This is the section where the application names and menus are displayed. The content zone contains the items selected from the menu, while the footer zone contains the project's or university's name.

The dashboard system is divided into three sections: the Side Menu, the Header Zone, and the Content Zone.

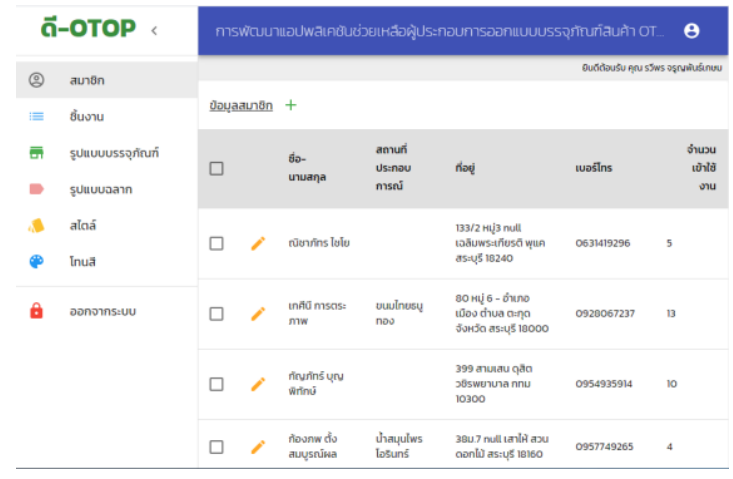

Figure 4. Administration page

As illustrated in Figure 4, the Content Zone will change in accordance with the Side menu. When a Content Zone member is selected, the names of all members in that system are displayed.

\section{RESUlTS AND DisCUSSION}

The research findings were based on a purposive sampling of 400 consumers and entrepreneurs in Saraburi Province. As a result of the research, it was found that:

1. Demands of entrepreneurs regarding OTOP product packaging. Entrepreneurs desire a redesign of their packaging. The desired packaging characteristics are attractive, robust, capable of protecting the product, environmentally friendly, exotic, and modern. A web application design will also be beneficial. They necessitate the use of web applications on mobile devices and computers.

2. Developing a conceptual framework of web applications for packaging design. It can be summarized as a picture of the conceptual framework development of web applications to assist entrepreneurs in designing OTOP products for the world as follows: 
The International Journal of Multimedia \& Its Applications (IJMA) Vol.13, No. 5, October 2021

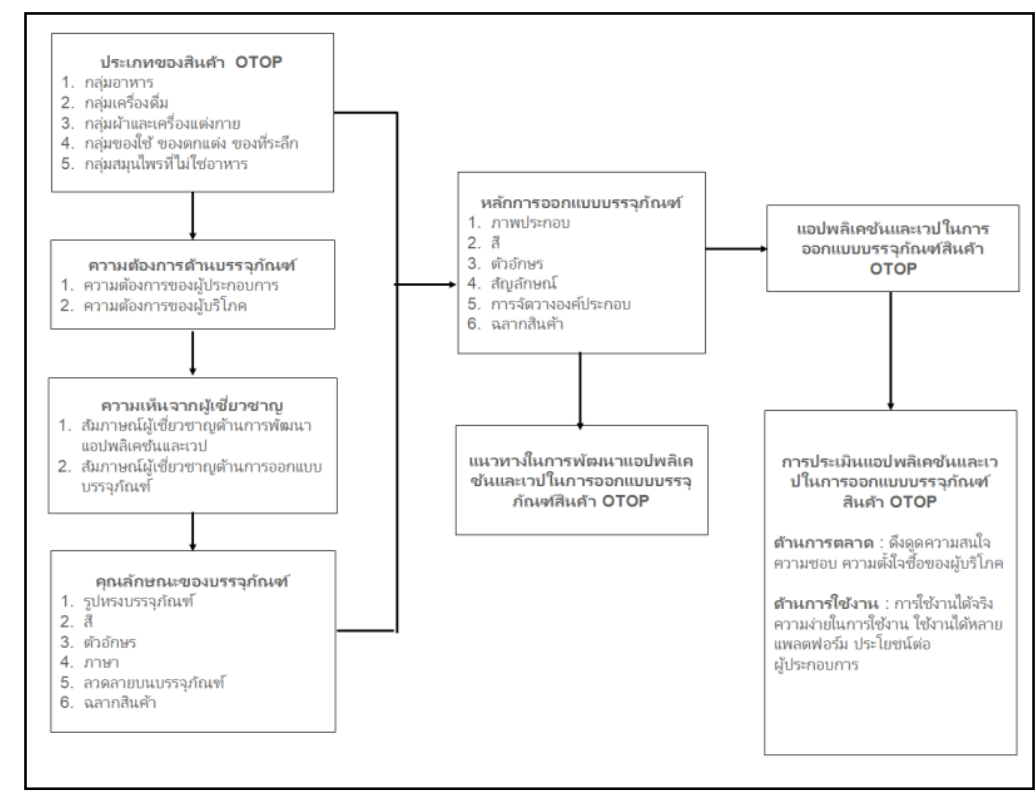

Figure 5. Conceptual framework of a web application for packaging design.

3. As a result of the web application development for packaging design, five experts provided their opinions. Expert opinions on overall quality were found to be excellent $(\bar{x}=4.72, \mathrm{SD}=$ 0.32 ), as detailed in the table. 1

Table 1. Evaluation results for the development of a web application for packaging design

\begin{tabular}{|c|c|c|}
\hline \multirow[t]{2}{*}{ Items } & \multicolumn{2}{|c|}{ Results } \\
\hline & $\bar{x}$ & S.D. \\
\hline 1. The web application is user-friendly. & 5.00 & 0.00 \\
\hline $\begin{array}{l}\text { 2. The web application is stable and is suitable for the } \\
\text { use. }\end{array}$ & 3.80 & 0.83 \\
\hline 3. The packaging style is modern. & 5.00 & 0.00 \\
\hline $\begin{array}{l}\text { 4. The web application can be used on a variety of } \\
\text { platforms. }\end{array}$ & 5.00 & 0.00 \\
\hline $\begin{array}{l}\text { 5. The web application's colour scheme is appropriate } \\
\text { for the intended audience. }\end{array}$ & 4.80 & 0.44 \\
\hline 6. The web application's screen size is appropriate. & 4.20 & 0.44 \\
\hline 7. The website is beneficial to entrepreneurs. & 5.00 & 0.00 \\
\hline 8. You are satisfied with the web application's overview. & 5.00 & 0.00 \\
\hline Total & 4.72 & 0.32 \\
\hline
\end{tabular}

The results of three individuals' web application performance tests for packaging design efficiency (E1/E2) were 52.33/55.56. After testing a small group of nine participants for efficiency of 64.44/67.79, and a field test of 30 people for efficiency of $80.83 / 81.45$, it was determined that they were effective according to the $80 / 80$ criteria. Details are shown in Table 2 . 
The International Journal of Multimedia \& Its Applications (IJMA) Vol.13, No. 5, October 2021

Table 2. Results of Performance Testing on a Web Application for Packaging Design

\begin{tabular}{|c|c|c|c|c|c|}
\hline \multirow[t]{2}{*}{ Tests } & \multirow{2}{*}{$\begin{array}{c}\text { Number of } \\
\text { entrepreneurs }\end{array}$} & \multicolumn{2}{|c|}{$\begin{array}{l}\text { Scores on the In-Study Test } \\
\text { (E1) on a 100-point scale }\end{array}$} & \multicolumn{2}{|c|}{$\begin{array}{c}\text { Scores on the Post-Study } \\
\text { Test (E2) on a 30-point } \\
\text { scale }\end{array}$} \\
\hline & & $\bar{x}$ & Percentage & $\overline{\boldsymbol{x}}$ & Percentage \\
\hline Individual & 3 & 52.33 & 52.33 & 16.68 & 55.56 \\
\hline Group & 9 & 64.44 & 64.44 & 20.34 & 67.79 \\
\hline Fieldwork & 30 & 80.83 & 80.83 & 24.44 & 81.45 \\
\hline
\end{tabular}

4. In the assessment item, entrepreneurs' overall satisfaction with the use of web applications for packaging design $(\bar{x}=4.78$, S.D. $=0.24)$ was excellent. It enables you to design in a variety of ways. The assessment outcome $(\bar{x}=3.60$, S.D. $=0.54)$ was considered to be moderate. Additionally, it excels in other areas. Consumers and entrepreneurs have suggested that packaging and labeling options should be expanded, as well as the use of more colors. As specified in Table 3

Table 3. Entrepreneurs' satisfaction with the use of web-based packaging design applications.

\begin{tabular}{|l|c|c|}
\hline \multicolumn{1}{|c|}{ Items } & \multicolumn{2}{c|}{ Results } \\
\cline { 2 - 3 } & $\overline{\boldsymbol{x}}$ & S.D. \\
\hline 1. The web application is user-friendly. & 5.00 & 0.00 \\
\hline 2. The web application's design is appealing. & 5.00 & 0.00 \\
\hline 3. The packaging style is modern. & 4.80 & 0.44 \\
\hline $\begin{array}{l}\text { 4. The web application can be used on a variety } \\
\text { of platforms. }\end{array}$ & 5.00 & 0.00 \\
\hline $\begin{array}{l}\text { 5. The web application facilitates packaging } \\
\text { design. }\end{array}$ & 4.80 & 0.44 \\
\hline $\begin{array}{l}\text { 6. The web application enables you to design in a } \\
\text { variety of ways. }\end{array}$ & 3.60 & 0.54 \\
\hline $\begin{array}{l}\text { 7. The web application saves money on the cost } \\
\text { of hiring a designer. }\end{array}$ & 5.00 & 0.00 \\
\hline 8. This web application is useful to you. & 5.00 & 0.00 \\
\hline $\begin{array}{l}\text { 9. You will recommend this web application to } \\
\text { your friends. }\end{array}$ & 4.80 & 0.44 \\
\hline $\begin{array}{l}\text { 10. You are satisfied with the web application's } \\
\text { overview. }\end{array}$ & 4.80 & 0.44 \\
\hline \multicolumn{1}{|c|}{ Total } & 4.78 & 0.24 \\
\hline
\end{tabular}

\section{Conclusions}

Packaging requirements for OTOP products. The following conclusions can be drawn from the findings: The majority of them are entrepreneurs of OTOP products, which include food and beverages, clothe and apparel, accessories/decorative items, and non-food herbs, respectively. The majority of OTOP entrepreneurs, up to 96.20 percent, desired a new packaging design.

Creating a conceptual framework for the web application that will be used to design OTOP product packaging for marketing promotion. The following conclusions can be drawn from the 
The International Journal of Multimedia \& Its Applications (IJMA) Vol.13, No. 5, October 2021

findings: 1. The name of the product. Users can type the product name into the web application's field for printing product names. To control the tone, users can select the font style, size, color, bold, italic, and color categorization. 2. The brand. A web application developer has created a pre-formatted package format, organized by category, that users can edit, insert images and detailed information, and customize with their own branding. The design must adhere to Thai and destination country laws. Must be suitable for packaging, have a pleasing appearance, be easy to read and comprehend. 3. Symbols or logos used in commerce. Currently, web applications and websites that assist entrepreneurs with product packaging design do not include the capability to design trade symbols or logos due to budget constraints. However, anticipating the issue, such capabilities should be added to web applications and websites that assist entrepreneurs if there is an opportunity to improve web application development. Packaging design is more comprehensive and efficient. 4. Product details, web applications have been designed with a prebuilt form, and the location of the product details has been blocked. Adjust the font style, size, and color to correspond to the categories of the web application and allow users to insert images and detailed information. 5. Promotional details are information that occurs on a periodic basis in order to increase sales or keep the business moving at a particular time. Entrepreneurs can use web applications and websites to design product packaging and the area on the product label that will be used to print promotional messages. Users can include images or symbols to enhance the readability of the text. 6. Images in web applications and websites to assist entrepreneurs with packaging design; users can choose from a pre-made design helper that categorizes products and pre-made images divided into graphics, background images, and icons. 7. Product components integrated into web applications and websites to assist entrepreneurs in internationalizing OTOP product packaging. On the package, there is a location block for product components. Users can type such messages. 8. Volume or quantity of web applications and websites designed to assist entrepreneurs with packaging design. For printing volume messages or product quantities, position blocks are provided. Users may make changes as necessary, categorize fonts, sizes, and colors and leave blank spaces in languages to make the text clear and easy to read. 9. Manufacturers' and suppliers' names in web applications and websites that assist entrepreneurs in designing product packaging. The manufacturer and supplier names are not visible. The user can type the text and customize the font style, size, color, and language selection. 10. According to experts, regulatory details such as production date and expiration date are designed to position regulatory details such as production date and expiration date while allowing users to modify the information to meet their specific needs.

The results of developing a web application for OTOP's product packaging design in order to promote marketing. The following conclusions can be drawn from the findings: It is possible to deploy web applications. Additionally, by polling entrepreneurs, the web application can help cut down on design costs. The evaluation of the suitability of web applications to assist entrepreneurs in designing OTOP product packaging for international distribution found that the overall suitability of web applications to assist entrepreneurs in packaging design is excellent $(\overline{\boldsymbol{x}}=4.72$, $\mathrm{SD}=0.32$ ). The evaluation results for the following items: the web application is user-friendly, the packaging style is modern, and the web application is useful to entrepreneurs are excellent ( $\bar{x}=5.00$, S.D. $=0.00)$, indicating that the web application is practical, and entrepreneurs can easily use it. Print and save formats should be added to allow for the saving of images as PNG and PDF files, as the development of web applications that render images is not entirely transparent in terms of file format rendering. As a result, it must be revised to make it clearer, in accordance with expert opinion.

Entrepreneurs' satisfaction with using a web application for OTOP product packaging design for marketing promotion. The research discovered that, on average, the effect of web application satisfaction was excellent $(\bar{x}=4.78$, S.D. $=0.24)$ due to easy to use, good looking, modern and using various platform, helping entrepreneurs to design package easier and reduce cost and increase 
The International Journal of Multimedia \& Its Applications (IJMA) Vol.13, No. 5, October 2021

competition capacity. In other areas, the evaluation results are excellent. Experts are asked to comment on the web applications, assess their suitability, and conduct interviews with consumers and entrepreneurs. In terms of web application usage, there have been numerous summaries, document reviews, and web application reviews conducted by experts, consumers, and entrepreneurs, all of which resulted in remarkably high satisfaction levels. In item; The web application enables you to design in a variety of ways., the evaluation result ( $\bar{x}=3.60, \mathrm{SD}=$ 0.54 ) is moderate due to consumer and entrepreneur preferences for patterns and colors. Web applications will need to diversify their designs to capture consumers' and entrepreneurs' attention.

\section{ACKNOWLEDGEMENTS}

Thank you so much for your support. As always, it was an honour and a pleasure to collaborate with Rajamangala University of Technology Phra Nakhon.

\section{REFERENCES}

[1] ChinASRI, W and Wasugree, S. (2015). "Web application development for multiple choice exam analysis ", VRU RESEARCH AND DEVELOPMENT JOURNAL SCIENCE AND TECHNOLOGY. Vol 10, No.1, pp1-17.

[2] Sushant Kumar Bhandi, (2018). "Web Application Development and Tackling the Problems", IOSR Journal of Computer Engineering, Vol 20, No. 3, pp63-68.

[3] M.Taylor, McWilliam, S. Wade and W. Anacoura, (2015), "A User Centre Website Development Approach", International Conference on, Troyes.

[4] Promwong, C. (2013). Testing the efficiency of media or teaching series. Silpakorn Education Science Research Journal, Vol 5, No.1, pp5-20.

[5] Yuangngoen. W, Saengrith. W, Sitthimongkolchai. N, Makeshin. S, Petsangsri.S, and Tuntiwongwanich. S, (2020), "Blended Learning Management of WordPress Website Development Skill for Communication Design Undergraduates Using The ADDIE Model". International Journal Industrial Education and Technology, Vol 1, No.1, pp50-58.

[6] Abhijit J, (2014), “Controlled Terms or Free Terms? A JavaScript Library to Utilize Subject Headings and Thesauri on the Web".Journal of Computing Sciences in Colleges, Vol 30, No.2, pp.139-141.

[7] Hardeep. K.D., (2020), "A Performance Comparison of RESTful Applications Implemented in Spring Boot Java and MS.NET Core". Virtual Conference on Engineering, Science and Technology (ViCEST) 2020, pp.1-7. 